LA-UR-01-3112

Approved for public release; distribution is unlimited.

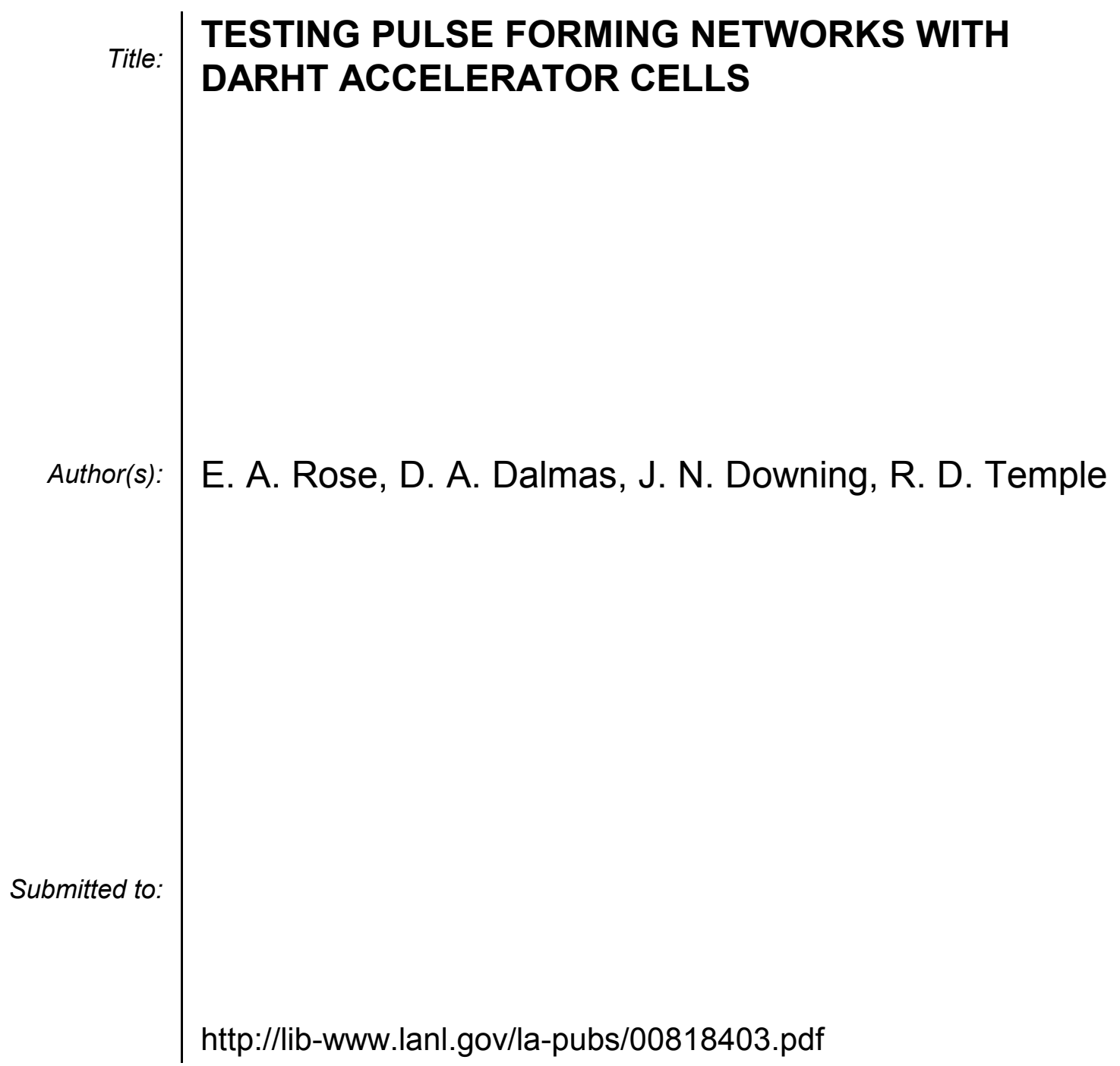

Los Alamos National Laboratory, an affirmative action/equal opportunity employer, is operated by the University of California for the U.S. Department of Energy under contract W-7405-ENG-36. By acceptance of this article, the publisher recognizes that the U.S. Government retains a nonexclusive, royaltyfree license to publish or reproduce the published form of this contribution, or to allow others to do so, for U.S. Government purposes. Los Alamos National Laboratory requests that the publisher identify this article as work performed under the auspices of the U.S. Department of Energy. Los Alamos National Laboratory strongly supports academic freedom and a researcher's right to publish; as an institution, however, the Laboratory does not endorse the viewpoint of a publication or guarantee its technical correctness. 


\title{
TESTING PULSE FORMING NETWORKS WITH DARHT ACCELERATOR CELLS
}

\author{
E. A. Rose, D. A. Dalmas, J. N. Downing, R. D. Temple \\ Los Alamos National Laboratory, P.O.Box 1663, Mail Stop P-939 \\ Los Alamos, NM 87545, USA
}

\section{Abstract}

The Dual Axis Radiographic Hydrotest Facility [DARHT] at Los Alamos will use two induction linacs to produce high-energy electron beams. The electron beams will be used to generate $\mathrm{x}$-rays from bremsstrahlung targets. The x-rays will be used to produce radiographs. The first accelerator is operational now, generating a 60nanosecond electron beam. The second accelerator is under construction. It will generate a 2-microsecond electron beam.

The 78 induction cells of the second axis accelerator will be driven by an equal number of pulse forming networks. Each pulse forming network [PFN] generates a nominal 200-kV, 2-microsecond pulse to drive an accelerator cell. Each pulse forming network consists of a set of four equal-capacitance sub-PFN's, stacked in a Marx configuration.

The PFN Test Stand was configured to test newly constructed accelerator cells under conditions of full voltage and pulse duration. The PFN Test Stand also explored jitter, prefire and reliability issues for a pulse forming network operated into a purely resistive load.

The PFN Test Stand provided experience operating a simple subsystem of the DARHT accelerator. This subsystem involved controls, diagnostics, data acquisition and archival, power supplies, trigger systems, core reset and a gas flow system for the spark gaps. Issues for the DARHT accelerator were investigated in this small-scale facility.

\section{INTRODUCTION}

The DARHT project involves collaboration between three national laboratories - Lawrence Berkeley National Laboratory, Lawrence Livermore National Laboratory and Los Alamos National Laboratory. While the facility is sited at Los Alamos, the majority of the equipment design and production is performed at the other two laboratories.

The pulsed power system for driving the accelerator cells was designed and produced by personnel at Lawrence Berkeley National Laboratory. The operating environment for that equipment, however, is peculiar to the DARHT facility in Los Alamos. The authors of this paper set up a test stand in Los Alamos to test and operate the pulse forming networks using the DARHT controls and data acquisition systems. In addition, this test stand is used to qualify for high voltage operation the forty accelerator cells that are fabricated at Los Alamos National Laboratory.

This test stand duplicates capabilities that are also available at Lawrence Berkeley National Laboratory. Our interest is directed toward exploring and anticipating the behavior of the pulse forming networks in the DARHT facility.

\section{THE TEST STAND}

There are two pulse forming networks at the test stand. One PFN is dedicated to jitter tests of the spark gaps and reliability testing. We connect that PFN to a 20-ohm resistive load. The other PFN is used to test accelerator cells. The two PFN's share power supplies, triggering, controls and diagnostics. Currently, only one PFN can be operated at a time. However, both PFN's could be operated together with the addition of a few cables.

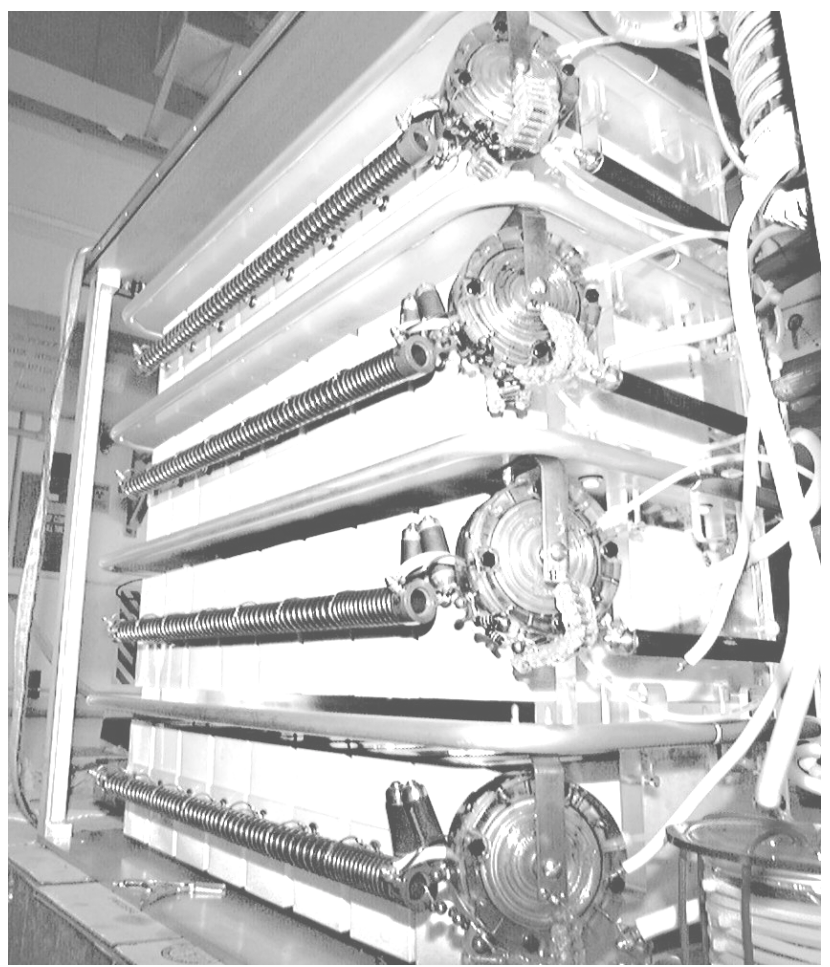

Figure 1. Pulse Forming Network. Capacitors [white] are connected by mutually coupled inductors and resistors to the spark gaps. 
The control system uses a commercial software package, Intellution FIX-32. The controls computer is interfaced to the equipment through Modicon Programmable Logic Controllers. We operate and monitor the high voltage power supplies, trigger units, dump relays and the gas control system for the PFN spark gaps through the controls computer.

The data acquisition system uses a commercial software package, Data Acquisition, Archival, Analysis, and Control [DAAAC], from Voss Scientific. We operate digitizers, time delay generators and time interval counters, mounted in a VXI crate, through DAAAC. Data is displayed and archived on the computer running DAAAC.

The controls hardware and the data acquisition hardware are located in separate relay racks. Trigger cables and trigger monitor cables between the racks are isolated by transformers to break ground loops. Diagnostic cables from the PFN and accelerator cell are threaded through ferrite cores to reduce common mode currents

Two features of the PFN's conspire to demand isolation of the controls and data acquisition hardware. First, the pulse length is longer than two microseconds. Our cable lengths are too short to allow transit time isolation. Second, we drive the accelerator cells into reverse saturation with an active reset pulse of 600 amperes and a risetime of 150 microseconds. This reset current will find all alternate paths back to the core reset power supply.

A gas control system provides dry air for the spark gaps. This system was built in-house. The air is provided by a compressor for the building and then dried with a regenerative desiccant system to below -40 degrees Celsius. Regulators and mass flow transducers are used to set the pressure and gas flow rates through the spark gaps. The gas control system is operated remotely from the control system.

\section{JITTER MEASUREMENTS}

The jitter requirement for the PFN system at DARHT is $20 \mathrm{~ns}$ for three sigma [ \pm 3 standard deviations]. The control system sends a master timing signal to the data acquisition relay rack. Triggers are sent from there to a high voltage trigger generator and the digitizers by a Highland Technology, model V980, 16-channel, time to digital converter [TDC], VXI module with 48-ps resolution. Event timing is recorded with a Highland Technology, model V951, 6-channel, digital delay generator [DDG], VXI module with 40-ps resolution.

Jitter is measured with two different methods. In the first method [TDC], the time is measured between a trigger pulse from the DDG and the arrival of a pulse monitor signal from the load. The pulse monitor signal is processed with a Philips Scientific, model 710, octal discriminator and a Philips Scientific, model 726, level translator to provide a TTL signal to the TDC. DAAAC records the information from the TDC.
In the second method [waveform], the time is measured on the Tektronix, TVS641A, waveform analyzer [digitizer]. The digitizer is triggered by the DDG. The pulse monitor signal is recorded on the digitizer at a rate of $1 \mathrm{~ns}$ per point. The time at $50 \%$ of peak amplitude is determined using a routine in DAAAC.

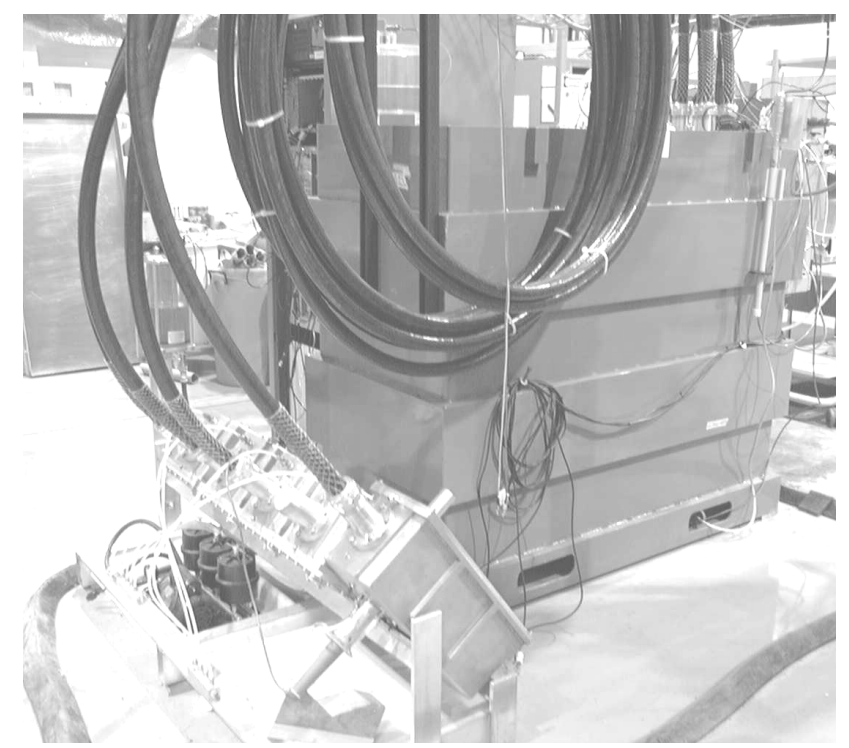

Figure 2. Jitter measurements. Four coiled drive cables connect the PFN to resistive loads in oil-filled compensation cans.

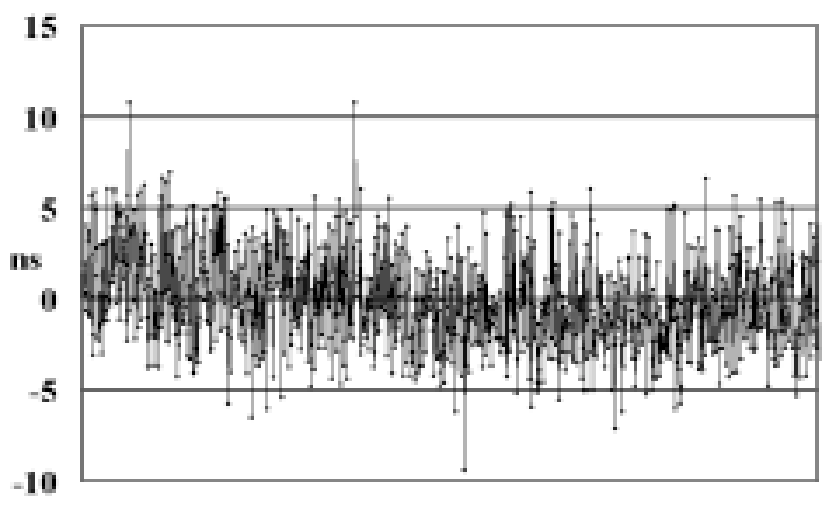

Figure 3. Pulse jitter about the average with TDC method. Standard deviation is $2.73 \mathrm{~ns}$ for 1000 shots.

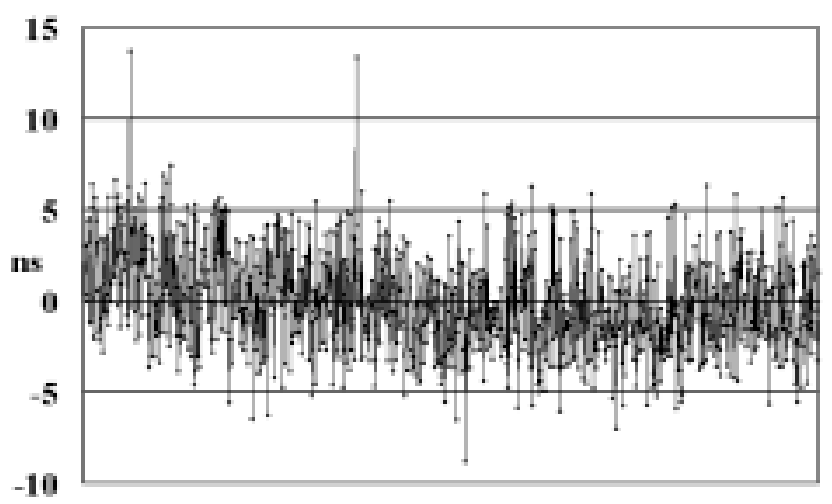

Figure 4. Pulse jitter about the average with waveform method. Standard deviation is $2.80 \mathrm{~ns}$. 


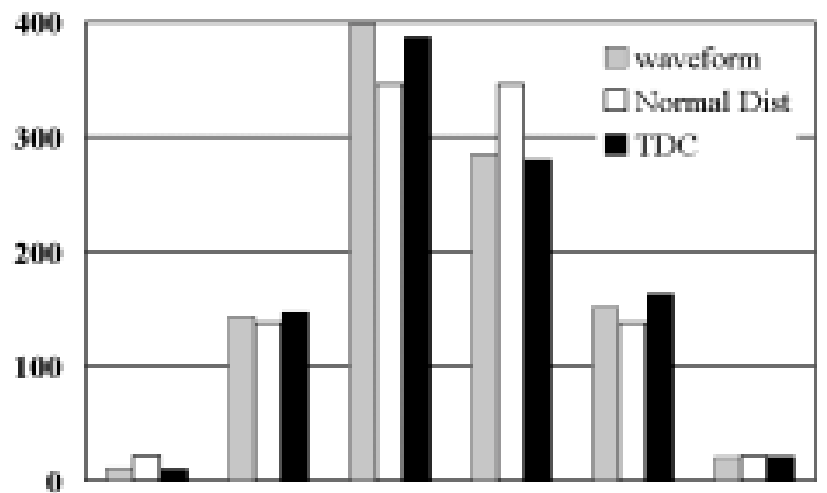

Figure 5. Comparison of jitter measurements with a normal distribution. Each bar represents a bin that is one standard deviation wide.

Tests were performed over a range of charge voltages on the PFN and pressures on the spark gaps. Typical data runs gathered 1000 shots at 6 shots per minute.

For $85 \mathrm{kV}$ charge [nominal $215 \mathrm{kV}$ into the load] and 86 psi absolute, a standard deviation of $2.73 \mathrm{~ns}$ was measured with the TDC method, and 2.80 ns was measured with the waveform method. The two methods gave essentially the same answer. The three-sigma values of $16 \mathrm{~ns}$ and $17 \mathrm{~ns}$ meet the jitter requirement.

\section{ACCELERATOR CELL TESTS}

Newly assembled accelerator cells are tested for high voltage integrity using the PFN test stand. Accelerator cells have a nominal operating point of $195 \mathrm{kV}$, so they are tested at $10 \%$ above nominal, or $215 \mathrm{kV}$. A $2,000-$ shot sequence is taken, at a rate of 6 shots per minute.

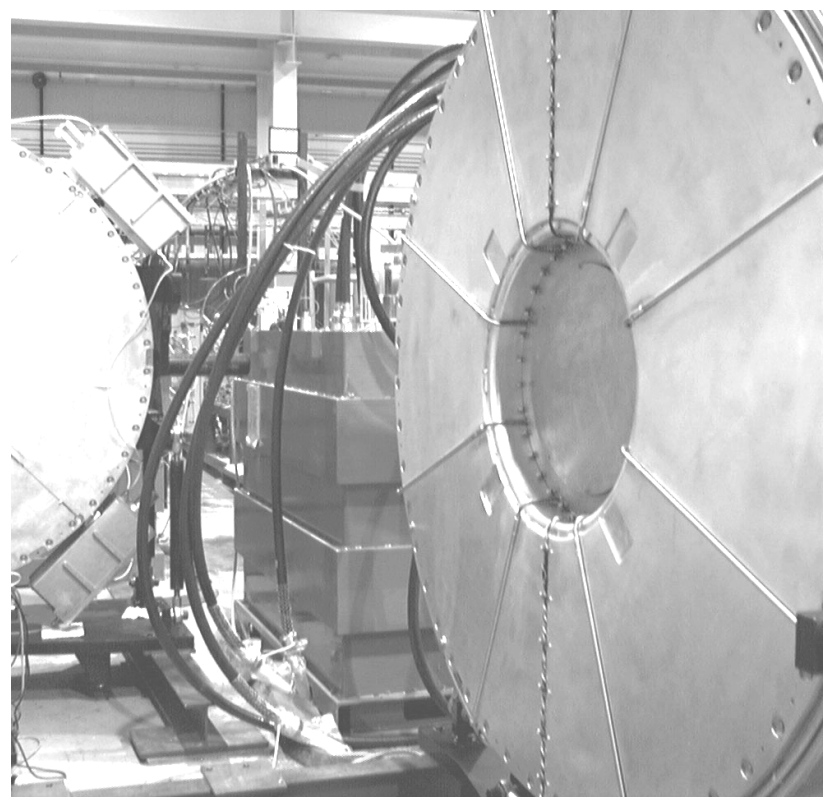

Figure 6. Accelerator cells await test at the PFN Test Stand.
Under test, the accelerator cell is positioned in a stand close to the PFN and put under vacuum in the low 10-7 Torr range. Four 70-ohm drive cables from the PFN are connected to the compensation cans that are attached to the accelerator cells. The compensation cans contain resistors [130 ohms per can] connected in parallel with the drive rods. The resistors determine the load characteristics for much of the pulse cycle, until the metglas in the accelerator begins to saturate, late in the pulse cycle. As the metglas saturates, more current flows as leakage current. The impedance of the PFN has a lower value late in the pulse to provide this higher current demand and maintain a constant voltage.

Voltage on the cell is monitored with a 10,000:1 resistive voltage divider in one of the compensation cans. Total current into the drive cables is monitored with a current transformer in the PFN.

Voltage and current measurements are obtained on opposite ends of the drive cables. This presents some difficulties with interpretation, because there are also reflections involved. For display purposes, the voltage and current waveforms are presented on a single plot, with coincident initial times. All the voltage waveforms presented reach a peak near $-200 \mathrm{kV}$ and have a shorter initial peak than the current waveforms.

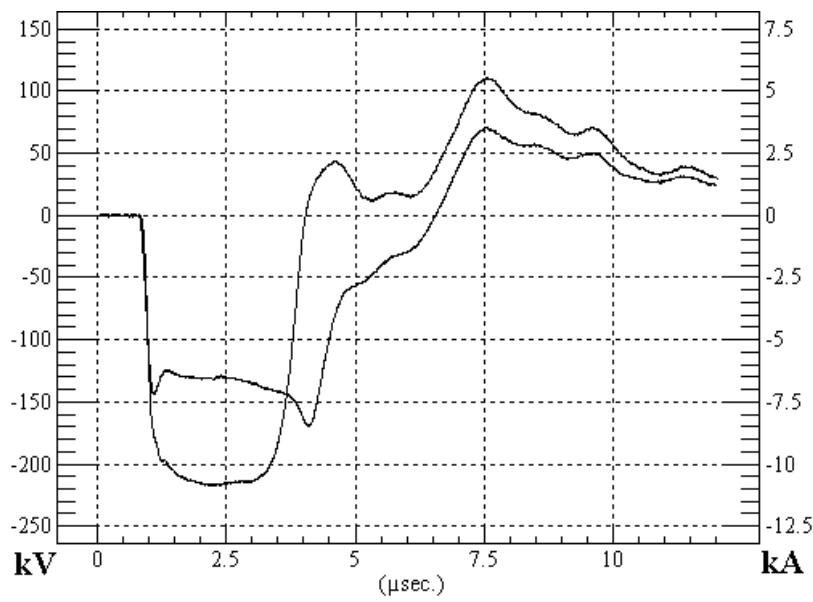

Figure 7. Normal voltage and current waveforms.

Typical failures during test are of two types.

External failures are indicated by a jump in pressure in the vacuum maintained in the accelerator cell. The most likely mechanism for this type of failure is an arc across the insulator on the vacuum side. Most frequently, this arc occurs after the main pulse, when the voltage has reversed polarity on the insulator. The voltage collapses and the current rings.

External failures typically "clean up" by themselves. A low voltage shot is taken after such a failure, to ensure proper reset of the core. Then testing at full voltage is resumed. If a proper reset is not performed, then failures are likely to continue, because the voltage reversal is exacerbated when reset of the metglas cores is incomplete. Rarely, one of these arcs occurs during the main pulse. 


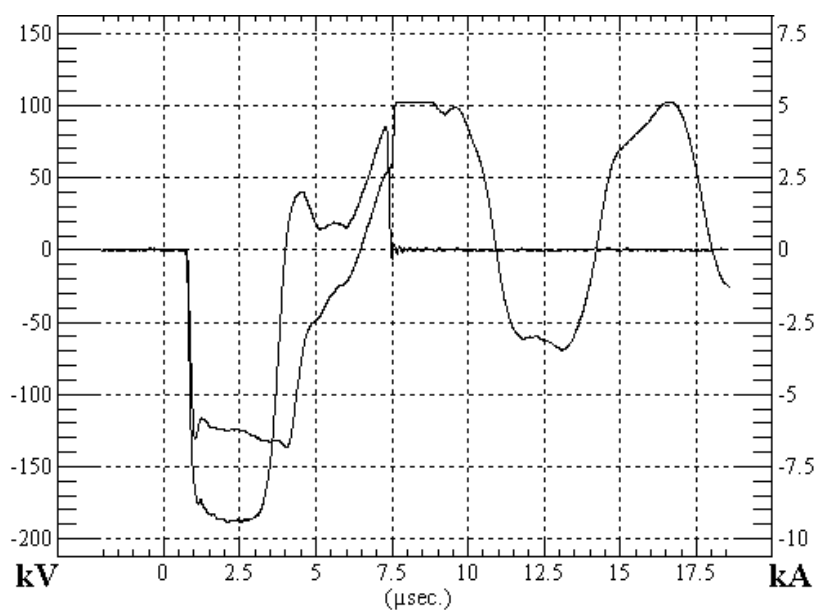

Figure 8. An arc across the insulator at 7.5 microseconds occurs during voltage reversal.

Internal failures are indicated by no jump in pressure in the vacuum. Occasionally, after such a failure, a bubble is observed leaving the accelerator cell and entering the expansion reservoir mounted on the top of the cell. This type of failure does not result in a short circuit, because voltage is still maintained at the drive rod. The current amplitude is greatly increased, indicating a reduction in impedance at the load - the accelerator cell. Oscillations in current and voltage follow the failure.

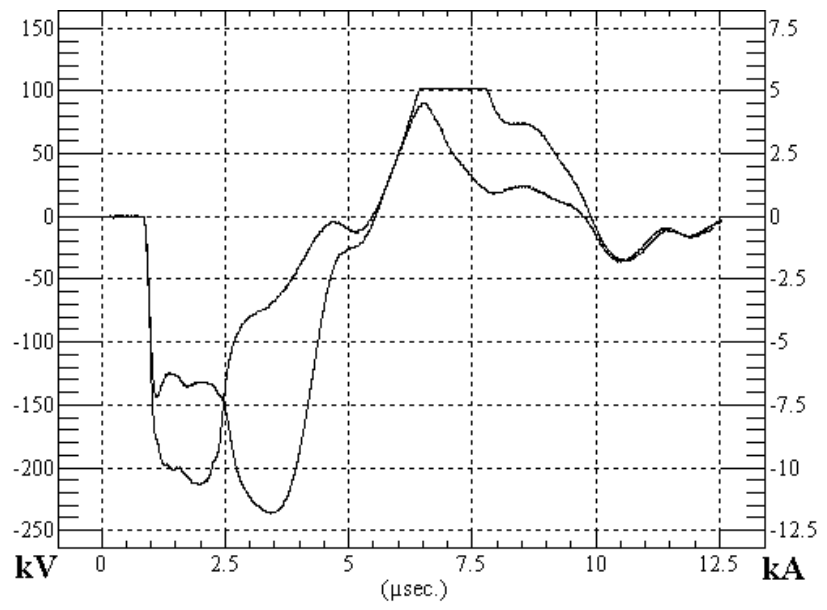

Figure 9. An internal failure occurs at 2 microseconds.

We have not pinpointed the locations of these failures. One accelerator cell suffered repeated internal failures and did not recover. It will be disassembled and examined for damage.

\section{OTHER TESTS}

\section{A. Calibration}

The PFN Test Stand has been used to calibrate the resistive voltage dividers that are installed in the compensation cans. In Figure 2 above, there are five compensation cans. The compensation can in the foreground is rigged with a Tektronix 6015 high voltage probe. That probe is used as a reference for calibration of a resistive voltage divider inside the compensation can. The test is performed in air, with a maximal applied voltage of $30 \mathrm{kV}$. A boss attached to the lid of the compensation can accepts a capacitive voltage probe or an electro-optic voltage probe, allowing tests of those units. Similar tests, at full voltage, can be performed using an accelerator cell, with the compensation can filled with oil.

\section{B. PFN Modifications}

The PFN Test Stand has been used to examine the behavior of pulse forming networks as they might behave in the DARHT facility. In particular, a problem was discovered with a PFN operating at another facility. That PFN produced high voltage when the dump switch was closed. Safety considerations dictate that a dump of a PFN proceed without producing high voltage.

Investigation at the PFN Test Stand indicated that two mechanisms could be responsible.

First, noise from the dumping of the PFN capacitors fires the high voltage trigger unit. The trigger unit then fires the switches in the PFN and produces high voltage on the drive cables.

Second, the spark gaps self-fire on dumping the PFN. A circuit model indicates that the rapid dumping of the capacitors unbalances the midplane spark gaps. The midplane potential is $40 \mathrm{kV}$ for an $80 \mathrm{kV}$ charge. When the capacitors are dumped through the charging resistor string, the electrodes of the topmost spark gap drop by 20 $\mathrm{kV}$. The bias resistors do not keep up with this rapid voltage change, leaving the midplane potential at $40 \mathrm{kV}$. A $60-\mathrm{kV}$ difference develops between the ground electrode of the spark gap and the midplane. If the spark gap pressure is low enough, the spark gap will self-fire.

The circuit model revealed that changing one charge resistor from $5 \mathrm{k}$-ohms to $100 \mathrm{k}$-ohms would reduce the effect by an order of magnitude. That change was implemented.

Preliminary tests at the PFN Test Stand with the modified pulse forming line show that the spurious PFN firing on dump no longer occurs.

\section{CONCLUSION}

The Pulse Forming Test Stand has produced data in support of the DARHT project. System jitter has been measured and meets requirements. New accelerator cells have been tested and qualified for service. Issues involving controls, grounding, calibration and PFN operation have also been addressed.

\section{ACKNOWLEDGEMENT}

This work was performed under the auspices of the U.S. Department of Energy under contract W-7405-ENG-36. 